\title{
Investigation of stoichiometric methane/air/benzene $(1.5 \%)$ and methane/air low pressure flames
}

\author{
Laurent Dupont ${ }^{\mathrm{a}}$, Abderrahman El Bakali ${ }^{\mathrm{a}}$, Jean-François Pauwels ${ }^{\mathrm{a}}$, Isabelle \\ Da Costa ${ }^{\mathrm{b}}$, Philippe Meunier ${ }^{\mathrm{b}}$, Henning Richter ${ }^{\mathrm{c}, *}$ \\ ${ }^{a}$ Université des Sciences et Technologies de Lille, UMR 8522 "Physicochimie des Processus de Combustion", Centre \\ d'Etudes et de Recherches Lasers et Applications, F-59655 Villeneuve d'Ascq, France \\ ${ }^{\mathrm{b}}$ Gaz de France, Direction de la Recherche, B.P. 33, F-93211 Saint Denis la Plaine Cedex, France \\ ${ }^{\mathrm{c}}$ Department of Chemical Engineering, Massachusetts Institute of Technology, Cambridge, MA 02139-4307, USA
}

Received 28 October 2002

\begin{abstract}
Benzene depletion in a laminar premixed flat stoichiometric low-pressure methane/air/benzene (1.5\%) flame was investigated using a recently developed kinetic model that has been tested for low-pressure combustion of acetylene, ethylene, and benzene. Experimental flame structures of two stoichiometric methane/air flames $\left(\mathrm{v}=34.2 \mathrm{~cm} \mathrm{~s}^{-1}, 5.33\right.$ $\mathrm{kPa}$ ) with and without the addition of $1.5 \%$ of benzene were measured previously by means of molecular beam sampling using mass spectrometry as well as gas chromatography coupled to mass spectrometry as analytic tools. Model computations were conducted using the Premix code within the Chemkin software package. Experimental temperature profiles were used as input. The analysis of rates of production of selected species allowed for the identification of major formation and depletion pathways. The predictive capacility of the model was assessed in both flames. Good to excellent agreements between predictions and measured mole fraction profiles were obtained for reactants, intermediates, and products such as methane, $\mathrm{O}_{2}$, methyl, $\mathrm{H}, \mathrm{OH}, \mathrm{CO}, \mathrm{CO}_{2}$. and $\mathrm{H}_{2} \mathrm{O}$. Benzene depletion and the formation and consumption of intermediates such as cyclopentadiene were predicted correctly. According to the model, methyl is exclusively formed by hydrogen abstraction from methane and subsequently oxidized by reaction with $\mathrm{O}$ to formyl, (1) $\mathrm{CH}_{3}+\mathrm{O} \leftrightarrows \mathrm{HCO}+\mathrm{H}_{2}$, and formaldehyde, (2) $\mathrm{CH}_{3}+\mathrm{O} \leftrightarrows \mathrm{CH}_{2} \mathrm{O}+\mathrm{H}$, the latter channel being the dominant one. Benzene consumption occurred mainly by hydrogen abstraction with $\mathrm{OH}$ and $\mathrm{H}$ as reactant but also the contribution of its oxidation by $\mathrm{O}$ to phenoxy was significant. Phenol and phenoxy chemistries are strongly coupled, unimolecular decay of phenoxy to cyclopentadienyl radicals and $\mathrm{CO}$ is the dominant consumption route. Small PAH are predicted to be formed in the reaction zone, followed by complete depletion in the postflame region. The pressure dependence of the dominant dimethylether formation (32) $\mathrm{CH}_{3}+\mathrm{CH}_{3} \mathrm{O} \leftrightarrows \mathrm{CH}_{3} \mathrm{OCH}_{3}$ was found to be significant and assessed by means of Quantum Rice-Ramsperger-Kassel (QRRK) analysis. () 2003 The Combustion Institute. All rights reserved.
\end{abstract}

Keywords: Methane; Benzene; PAH

\section{Introduction}

The presence of fine particles generated by incomplete combustion processes in atmospheric aero-

* Corresponding author. Tel.: +1-617-253-6536; fax: +1-617-258-5042.

E-mail address: richter@mit.edu (H. Richter). sols is of significant health concern due to their association with lung cancer and cardiopulmonary disease shown in epidemiological studies [1,2]. Poly- 
Table 1

Flame parameters. a) Flame I: laminar premixed stoichiometric methane/air flame b) Flame II: laminar premixed stoichiometric methane/air/benzene (1.5\%) flame

\begin{tabular}{lllllll}
\hline Flame & $\begin{array}{l}\text { Cold gas velocity v, } \\
25^{\circ} \mathrm{C}\left(\mathrm{cm} \mathrm{s}^{-1}\right)\end{array}$ & $\begin{array}{l}\text { Pressure } \\
(\mathrm{kPa})\end{array}$ & $\mathrm{X}_{\mathrm{CH} 4}$ & $\mathrm{X}_{\text {benzene }}$ & $\mathrm{X}_{\mathrm{O}_{2}}$ & $\mathrm{X}_{\mathrm{N}_{2}}$ \\
\hline Flame I & 34.2 & 5.33 & 0.111 & 0.00 & 0.222 & 0.667 \\
Flame II & 34.2 & 5.33 & 0.060 & 0.015 & 0.230 & 0.695 \\
\hline
\end{tabular}

cyclic aromatic hydrocarbons (PAH) are thought to be key precursors of soot [3]. PAH have been quantified in atmospheric aerosol samples [4] and many of them have been found to be mutagenic [5]. The minimization of pollutants such as soot and PAH in the exhaust of combustion devices requires the control and therefore a detailed understanding of chemical reaction pathways. The presence of PAH and soot in the exhaust of hydrocarbon combustion is the overall result of competing processes leading to the growth of PAH of increasing size and ultimately to soot as well as their depletion. Depending on the local conditions, PAH, soot and their precursors can be oxidized within the flame before release. Kinetic modeling by means of complex reaction networks allows for the assessment of chemical processes inherent to hydrocarbon oxidation and pyrolysis. Detailed reaction mechanisms have been developed and tested for premixed combustion of different fuels such as methane [6], acetylene [7,8], ethylene [7,9,10], ethane [6], propane [11], 1,3-butadiene $[12,13]$ and benzene [14-18] by comparison to experimental flame structure data. The quality of a kinetic model can be assessed by its capability to predict correctly experimental data, particularly the evolution of concentrations of reactants, products and intermediates, over a large range of experimental conditions such as fuel type and equivalence ratio. Thus, Lindstedt and Skevis [8] tested their kinetic mechanism for six lean $(\phi=0.12)$ to sooting $(\phi$ $=2.50$ ) laminar, low-pressure acetylene flames.

The reaction network used in the present work has been developed and tested by comparison of model predictions with experimental mole fraction profiles of stable and radical species measured in four acetylene $(\phi=2.40)$, ethylene $(\phi=0.75, \phi=1.90)$ and benzene $(\phi=1.80)$ premixed flat low-pressure flames using molecular beam sampling coupled to mass spectrometry (MBMS) [19].

In the present work, the depletion of benzene in a stoichiometric methane/air/benzene (1.5\%) flame was investigated. Combustion of methane, a major compound of natural gas, is of significant practical importance. Due to enhanced radiative heat release, the presence of soot particles can be desirable in practical devices before their release from the flame while soot and PAH remaining in the exhaust gas represent a major environmental concern. Complex mixing patterns in practical systems can lead to a large range of different local conditions, for instance equivalence ratios and temperatures. Before the attempt of describing such complex systems, a detailed understanding of the chemical processes is required. For this purpose, the combustion of model compounds, representative for practical fuels, under welldefined conditions and setups has to be investigated. For instance, a quantitative understanding of the oxidation of small aromatic species such as benzene is needed in order to assess the competition between the depletion of such compounds and their growth to PAH of increasing size and ultimately to soot.

In the present work, a recently developed kinetic model has been used for the analysis of benzene depletion in a laminar premixed stoichiometric methane/air low-pressure flame. The model has been tested for premixed low- pressure combustion of acetylene, ethylene and benzene [19]. A good predictive capability was observed for reactants, products and intermediates, including radical species [19]. The oxidative depletion of all three fuels under fuel-rich conditions was investigated and, in addition, a lean ethylene flame was analyzed. Also, the formation of single-ring aromatics was assessed quantitatively in the case of aliphatic fuels, ie, acetylene and ethylene [19].

\section{Approach}

Flame structures of two laminar premixed flat stoichiometric methane/air (Flame I) and methane/ air/benzene (Flame II) low-pressure flames ( $\mathrm{v}=34.2$ $\mathrm{cm} \mathrm{s}^{-1}, 5.33 \mathrm{kPa}$ ) were measured recently [20]. In the latter case, $1.5 \%$ of benzene was added to the cold gas mixture taking into account the contribution of benzene to the equivalence ratio, ie, the overall $\phi$ was kept at unity. Therefore, the mole fraction of methane in the initial mixture had to be reduced from $11.1 \%$ in the reference flame to $6 \%$ in the seeded flame. The parameters of both flames are summarized in Table 1 . Sampling was conducted by molecular beam with 


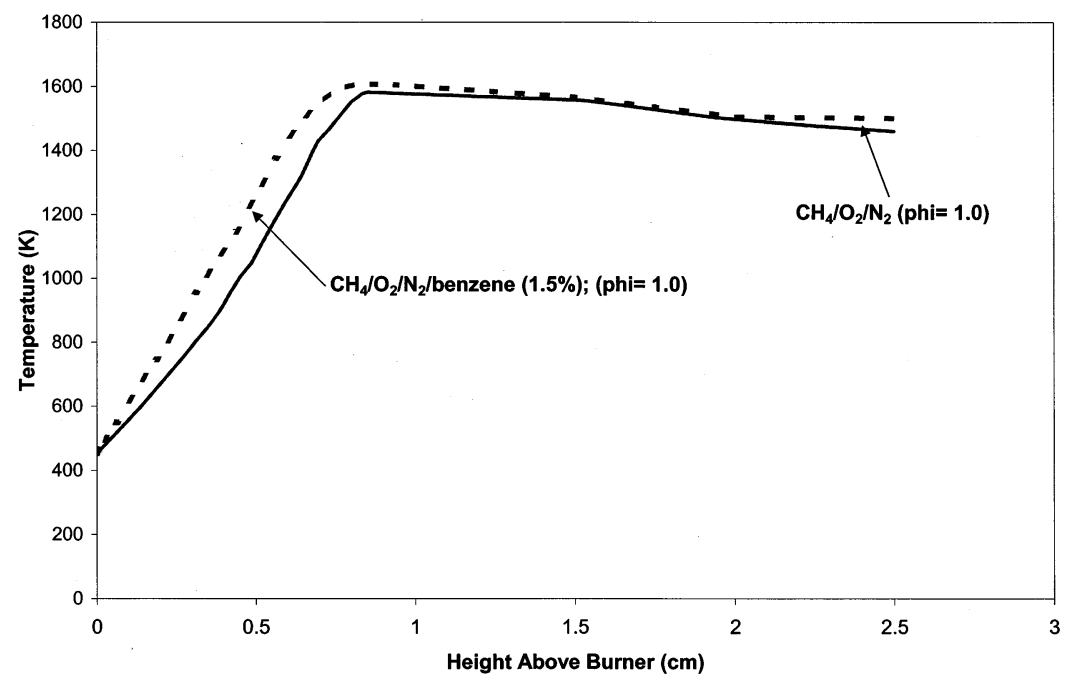

Fig. 1. Experimental temperature profiles [20]. — stoichiometric methane/air flame (Flame I). ${ }^{\cdots}$ stoichioimetric methane/air/ benzene $(1.5 \%)$ flame (Flame II).

subsequent online analysis by mass spectrometry (MBMS) and, alternatively, by gas chromatography using thermal conductivity and flame ionization detectors (GC-TCD-FID) and a mass spectrometric detector (GC-MS). The use of two complementary analytical techniques allowed for the identification of radical intermediates (by MBMS), essential for a detailed understanding of the combustion chemistry, and of species of identical mass such as cyclic and linear $\mathrm{C}_{5} \mathrm{H}_{6}$ or $\mathrm{C}_{6} \mathrm{H}_{6}$ species (by GC-MS). Detection limits of both techniques were at mole fractions of $\approx 5 \times 10^{-7}$ for stable species. Due to the necessity to operate the MBMS system at reduced ionization potentials to avoid fragmentation of parent molecules, detection limits of radical species are higher but depend on the specific conditions. Radical mole fractions of close to $1 \times 10^{-5}$ could be detected in the present work. Temperature profiles were measured by means of a coated $\mathrm{Pt} / \mathrm{Rh} 6 \%-\mathrm{Pt} / \mathrm{Rh} 30 \%$ thermocouple located $0.2 \mathrm{~mm}$ upstream the tip of the sampling probe. Radiative heat losses were taken into account by electrical compensation. Details of the experimental procedure were described previously [21,22].

A recently developed kinetic model [19] was used for the investigation of reaction pathways in methane combustion and benzene depletion under such conditions. Thermodynamic and kinetic property data were updated using most recent literature, density functional theory (DFT) and ab initio computations on a CBS-Q and CBS-RAD level. Quantum RiceRamsperger-Kassel (QRRK) analysis was conducted to determine pressure-dependent rate constants of chemically activated reactions $[19,23]$. The reaction mechanism and the corresponding thermodynamic property data, both carefully documented, are provided in the supplementary information of [19] and are available electronically $[19,24]$. All model computations were conducted with the Premix code within the Chemkin software package [25] using experimental temperature profiles (Fig. 1). The associated postprocessor was used for the determination of rates of production of selected species, ie, the contribution of specific reactions to their formation and consumption. The model attempts the description of the studied combustion systems using the best available thermodynamic and kinetic property data for each species and individual reaction step; therefore no adjustments were made in the present work. However, pressure dependence of dimethylether formation, not investigated previously, has been taken into account in the present work.

Quantitative measurements, particularly of species with concentrations close to the detection limit and of radicals, are challenging. Despite the excellent reproducibility found in the present work, uncertainties of up to $30 \%$ for some species, such as hydrogen radicals, cannot be excluded. Experimental temperature profiles were used for all model calculations, therefore, the impact of possible uncertainties was assessed. For instance, even an increase of $100 \mathrm{~K}$ of all temperatures led only to an insignificant increase of predicted maximum mole fractions while most profiles were shifted by 1 to $1.5 \mathrm{~mm}$ toward the burner. 


\section{Results}

\subsection{Methane combustion}

Meaningful investigation of benzene depletion in a seeded premixed methane/air flame necessitates the accurate description of methane oxidation chemistry. A high level of predictive capability for methane combustion is required from kinetic models due to the practical importance of methane and its formation as intermediate in the case of other fuels. Model predictions for reactants, products, and intermediates were compared to mole fraction profiles measured in the unseeded reference flame. Measured and computed mole fractions profiles of methane, $\mathrm{O}_{2}$, methyl, $\mathrm{H}, \mathrm{H}_{2}, \mathrm{OH}, \mathrm{CO}, \mathrm{CO}_{2}$, and propane $\left(\mathrm{C}_{3} \mathrm{H}_{8}\right)$ are shown in Fig. 2 to 4. Original experimental data points subsequent to calibration are given. No fitting was performed in order to allow the assessment of the reproducibility of the experimental procedure. Nearly complete methane consumption beyond approximatively $0.9 \mathrm{~cm}$ from the burner was correctly predicted by the model and a computed oxygen mole fraction of about 0.02 remaining in the postflame zone is in excellent agreement with the experimental findings. The determination of rates of production showed hydrogen abstraction to methyl to be the only significant methane consumption route. Relative contributions decrease from reactions with $\mathrm{OH}$ and $\mathrm{H}$ (both $\approx 40 \%$ of the maximum consumption rate) to that with $\mathrm{O}$. Shape, peak location and value of the methyl mole fraction profile was well predicted (Fig. 2). Its rates of production showed its exclusive formation from methane while (1) $\mathrm{CH}_{3}+\mathrm{O} \leftrightarrows \mathrm{HCO}+\mathrm{H}_{2}$, and (2) $\mathrm{CH}_{3}+\mathrm{O} \leftrightarrows \mathrm{CH}_{2} \mathrm{O}+\mathrm{H}$ were found to be the only significant consumption pathways. Using kinetic data based on the total rate constant measured by Lim and Michael [26] and the branching ratio determined by Marcy et al. [27], formation of formaldehyde $\left(\mathrm{CH}_{2} \mathrm{O}\right)$ was identified as dominant product channel. Subsequently, formaldehyde is depleted by hydrogen abstraction to $\mathrm{HCO}$ via reaction with $\mathrm{H}$ $(\approx 75 \%)$ and $\mathrm{OH}(\approx 20 \%)$. Unimolecular hydrogen loss and hydrogen abstraction by $\mathrm{H}, \mathrm{O}_{2}, \mathrm{OH}$, and $\mathrm{CH}_{3}$ to $\mathrm{CO}$ are the only significant $\mathrm{HCO}$ consumption and $\mathrm{CO}$ formation routes. $\mathrm{CO}$ consumption and $\mathrm{CO}_{2}$ formation were found to occur exclusively via (3) $\mathrm{CO}+\mathrm{OH} \leftrightarrows \mathrm{CO}_{2}+\mathrm{H}$. The equilibrium constant of reaction (3) depends strongly on the temperature. Consistent with the encouraging quality of the computed $\mathrm{H}$ and $\mathrm{OH}$ profiles (Fig. 3), the good agreements for both $\mathrm{CO}$ and $\mathrm{CO}_{2}$ model predictions with experimental data (Fig. 4), indicate the accuracy of the temperature profile used as input for the model computations. Hydrogen abstraction reactions with $\mathrm{H}$ radicals from methane, $\mathrm{CH}_{2} \mathrm{O}$ and $\mathrm{HCO}$ were found to play an important role. The good agreement between prediction and experiment for molecular hydrogen (Fig. 3) provides evidence of the correct thermodynamic description of these hydrogen abstraction reactions because of the non-negligible contribution of the reverse reaction under certain conditions.

Measured and computed mole fraction profiles of propane $\left(\mathrm{C}_{3} \mathrm{H}_{8}\right)$ are given in Fig. 4 in order to illustrate the formation and consumption of larger hydrocarbons in the case of stoichiometric methane combustion. (4) $\mathrm{C}_{2} \mathrm{H}_{5}+\mathrm{CH}_{3} \leftrightarrows \mathrm{C}_{3} \mathrm{H}_{8}$ was found to be the only major propane formation pathway. Ethyl $\left(\mathrm{C}_{2} \mathrm{H}_{5}\right)$ is formed by hydrogen abstraction from ethane $\left(\mathrm{C}_{2} \mathrm{H}_{6}\right)$ by $\mathrm{H}, \mathrm{OH}$ and $\mathrm{O}$ radicals. Self-combination of methyl, ie, (5) $\mathrm{CH}_{3}+\mathrm{CH}_{3} \leftrightarrows \mathrm{C}_{2} \mathrm{H}_{6}$, was identified as dominant ethane formation route. The depletion of propane occurs by hydrogen abstraction with $\mathrm{H}$ and $\mathrm{OH}$ to $\mathrm{n}$ - and i-propyl. Unimolecular decay of both propyl isomers to methyl and ethylene $\left(\mathrm{C}_{2} \mathrm{H}_{4}\right)$ and of i-propyl to propene $\left(\mathrm{C}_{3} \mathrm{H}_{6}\right)$ are dominant subsequent reactions.

\subsection{Benzene depletion}

Consumption pathways of benzene were investigated in a premixed low-pressure methane/air/benzene $(1.5 \%)$ flame. The fresh gas velocity was 34.2 $\mathrm{cm} \mathrm{s}^{-1}$, the pressure $5.33 \mathrm{kPa}$, and the overall equivalence ratio was $\phi=1.0$. Agreements between model predictions and experimental mole fractions for key species of methane oxidation such as $\mathrm{CH}_{4}, \mathrm{O}_{2}, \mathrm{H}, \mathrm{H}_{2}$, $\mathrm{O}, \mathrm{OH}, \mathrm{CH}_{3}, \mathrm{H}_{2} \mathrm{O}, \mathrm{CO}$, and $\mathrm{CO}_{2}$ are, similar to the above discussed reference flame, good to excellent. Comparisons between predicted mole fraction profiles and experimental data for methane, methyl and $\mathrm{O}$ radicals are shown in Fig. 5. Due the identical mass of methane and $\mathrm{O}$, ie, $16 \mathrm{amu}$, the oxygen profile was only available after complete methane depletion. The height above the burner where methane was totally consumed was determined by means of the gas chromatographic measurement of its profile as well as the use of an ionization potential below the appearance potential of $\mathrm{O}$, in the case of MBMS. In should be pointed out that despite the small benzene mole fraction of only $1.5 \%$ in the cold gas mixture, the perturbation of the methane/air system was significant. In fact, $60 \%$ of all carbon present in the flame came from the initial benzene feed. Benzene consumption was correctly reproduced by the model and is completed at $\approx 0.9 \mathrm{~cm}$ from the burner (Fig. 6). Major reactions involved in benzene depletion are summarized in Table 2. Phenol and cyclopentadiene $\left(\mathrm{C}_{5} \mathrm{H}_{6}\right)$ are intermediates in the benzene depletion process, both experimental and computed mole fraction profiles are plotted in Fig. 6. Gas chromatography coupled to mass spectrometry (GC-MS) allowed for the 


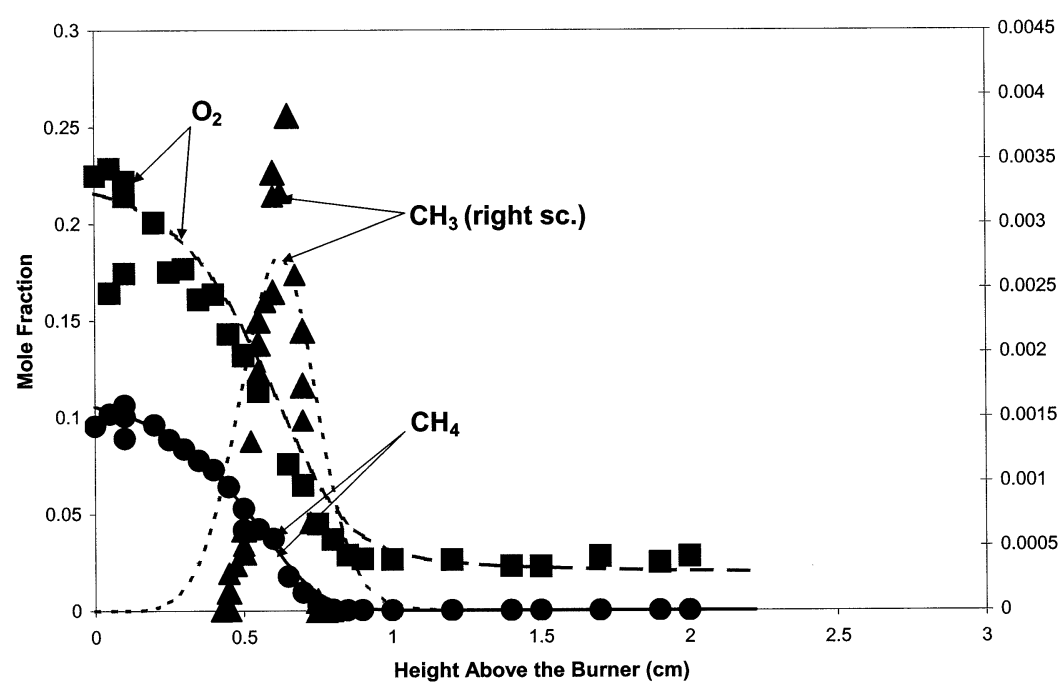

Fig. 2. Comparison between experimental mole fraction profiles and mode predictions in a stoichioimetric methane/air flame (Flame I).

$\mathrm{CH}_{4}:-$ (experiment [20]), - (prediction)

$\mathrm{O}_{2}:$ (experiment [20]), - - - (prediction)

$\mathrm{CH}_{3}$ : $\boldsymbol{\Delta}$ (experiment [20], right scale), ---- (prediction, right scale).

inambiguous identification of cyclopentadiene (and not linear $\mathrm{C}_{5} \mathrm{H}_{6}$ ) as dominant $\mathrm{C}_{5} \mathrm{H}_{6}$ species. Similarly, the presence of measurable amounts of $\mathrm{C}_{6} \mathrm{H}_{6}$ isomers other than benzene, ie, fulvene or linear species could be excluded by means of GC-MS. The agreement of shape, peak location, and value of the computed $\mathrm{C}_{5} \mathrm{H}_{6}$ mole fraction profile with the experimental one is excellent while the phenol peak mole fraction was about two-fold underpredicted. The rates of production of benzene (Fig. 7) showed hydrogen abstraction by $\mathrm{OH}$, ie, (6) benzene $+\mathrm{OH} \leftrightarrows$ phenyl $+\mathrm{H}_{2} \mathrm{O}$, to be the most important single benzene

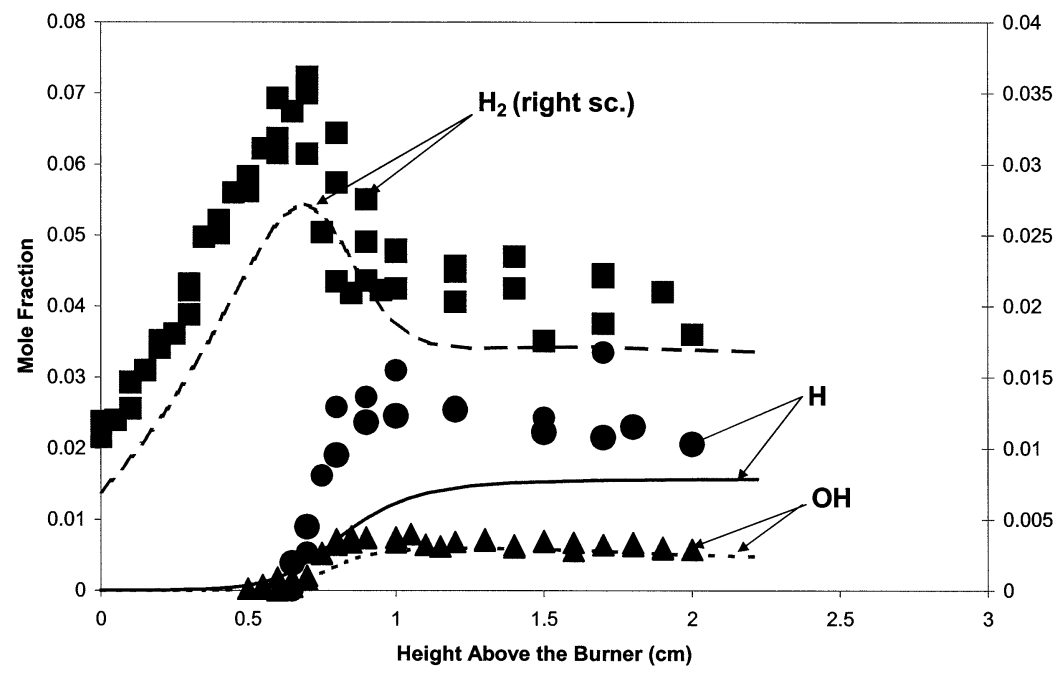

Fig. 3. Comparison between experimental mole fraction profiles and model predictions in a stoichoimetric methane/air flame (Flame I).

$\mathrm{H}:-$ (experiment [20], left scale), — (prediction, left scale)

$\mathrm{OH}:$ (experiment [20], left scale), - - - (prediction, left scale)

$\mathrm{H}_{2}: \boldsymbol{\Delta}$ (experiment [20], right scale), ---- (prediction, right scale). 


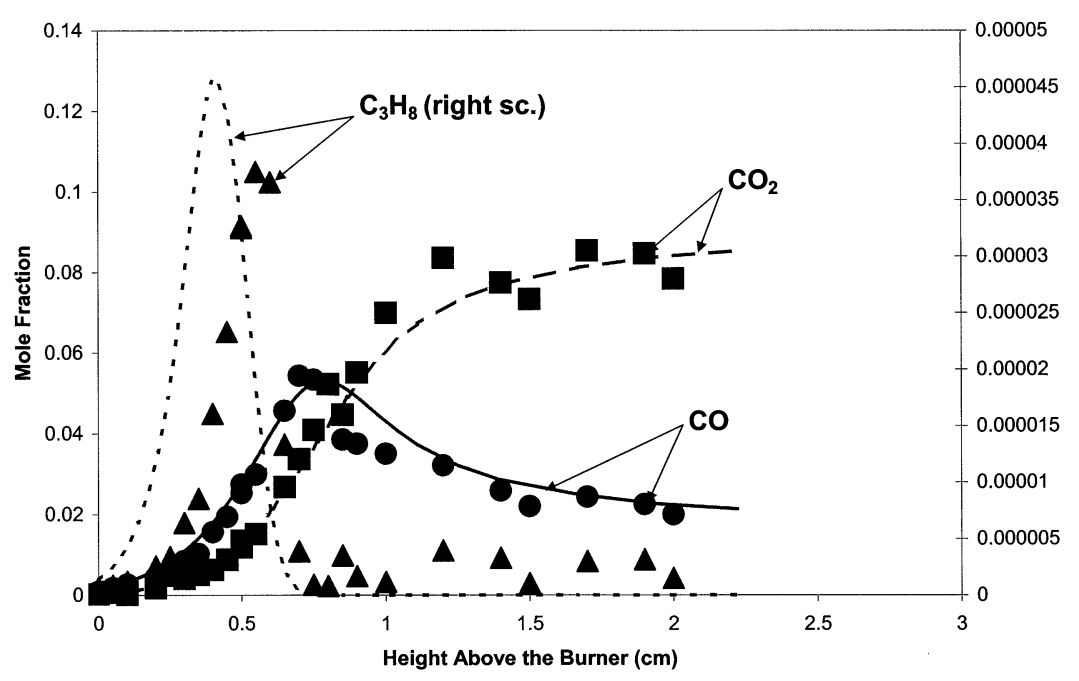

Fig. 4. Comparison between experimental mole fraction profiles and model predictions in a stoichoimetric methane/air flame (Flame I).

$\mathrm{CO}:-$ (experiment [20], left scale), - (prediction, left scale)

$\mathrm{CO}_{2}: \mathbf{\square}$ (experiment [20], left scale), - - - (prediction, left scale)

$\mathrm{C}_{3} \mathrm{H}_{8}: \boldsymbol{\Delta}$ (experiment [20], right scale), ---- (prediction, right scale).

consumption reaction. In addition, reaction with atomic oxygen leading to phenoxy, (7) benzene $+\mathrm{O}$ $\leftrightarrows$ phenoxy $+\mathrm{H}$, and hydrogen abstraction with $\mathrm{H}$ radicals, (8) benzene $+\mathrm{H} \leftrightarrows$ phenyl $+\mathrm{H}_{2}$, were found to be significant. While the resulting rate of benzene production was negative along the whole axis of the flame, (9) phenyl $+\mathrm{H} \leftrightarrows$ benzene and the reverse reaction of (10) benzene $+\mathrm{OH} \leftrightarrows$ phenol + $\mathrm{H}$ were benzene forming pathways. Consistent with the analysis of benzene consumption, the rates of production of phenyl showed reactions (6) and (8) to be its only significant formations routes. Phenyl oxidation by molecular oxygen, i.e., (11) phenyl $+\mathrm{O}_{2}$ $\leftrightarrows$ phenoxy $+\mathrm{O}$ was identified as the most important depletion reaction. QRRK analysis was performed in order to account for the pressure dependence of reaction $(11)[19,23]$ using the input parameters suggested by Dinaro et al. [34]. Phenyl oxidation to o-benzoquinone via reaction (12) phenyl $+\mathrm{O}_{2} \leftrightarrows$ o-benzoquinone $+\mathrm{H}$, suggested by Alzueta et al. [35], was found to contribute significantly to phenyl depletion. However, in other studies the role of benzoquinones has been found to remain questionable [19]. No benzoquinone could be identified experimentally [20] while peak mole fractions of $\approx 1.9 \times$ $10^{-5}$ and $\approx 1.7 \times 10^{-4}$ were predicted by the model for o- and p-benzoquinone, respectively. Oxidation to phenoxy by reaction with $\mathrm{OH}$, (13) phenyl $+\mathrm{OH} \leftrightarrows$ phenoxy $+\mathrm{H}$ and depletion to cyclopentadienyl by reaction with $\mathrm{O}$, (14) phenyl $+\mathrm{O} \leftrightarrows \mathrm{c}^{-} \mathrm{C}_{5} \mathrm{H}_{5}+\mathrm{CO}$ $[19,37]$ are also non-negligible phenyl depletion routes. In addition, also (15) i- $\mathrm{C}_{4} \mathrm{H}_{3}+\mathrm{C}_{2} \mathrm{H}_{3} \leftrightarrows$ phenyl $+\mathrm{H}$, suggested by Pope and Miller [38] and reaction with $\mathrm{H}$ to benzene, (9), contribute to phenyl $+\mathrm{H}$, consumption.

\subsection{Phenol and phenoxy}

The rates of production of phenol show (16) phenoxy $+\mathrm{H} \leftrightarrows$ phenol to be the only significant formation pathway. Hydrogen abstraction by $\mathrm{OH}$ and in a smaller extent by $\mathrm{H}$, leading to phenoxy, (17) phenol $+\mathrm{OH} \leftrightarrows$ phenoxy $+\mathrm{H}_{2} \mathrm{O}$ and (18) phenol $+\mathrm{H}$ $\leftrightarrows$ phenoxy $+\mathrm{H}_{2}$ are the dominant consumption routes. This observation indicates the strong coupling between phenol and phenoxy chemistries. Consistent with the above discussed benzene formation, also the reverse of reaction (10) benzene $+\mathrm{OH} \leftrightarrows$ phenol + $\mathrm{H}$ contributes significantly to phenol consumption. Another non-negligible phenol depletion route consists in its unimolecular decay to cyclopentadiene $\left(\mathrm{C}_{5} \mathrm{H}_{6}\right),(19)$ phenol $\leftrightarrows \mathrm{C}_{5} \mathrm{H}_{6}+\mathrm{CO}$.

In agreement with their significant contributions to the consumption of benzene and phenyl, (7) benzene $+\mathrm{O} \leftrightarrows$ phenoxy $+\mathrm{H},(11)$ phenyl $+\mathrm{O}_{2} \leftrightarrows$ phenoxy $+\mathrm{O}$ and (13) phenyl $+\mathrm{OH} \leftrightarrows$ phenoxy + $\mathrm{H}$ were found to be major phenoxy formation pathways. Phenoxy consumption occurs via reaction with hydrogen radicals to phenol (16) and unimolecular

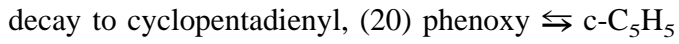
$+\mathrm{CO}$, confirming previous findings [19,32]. 


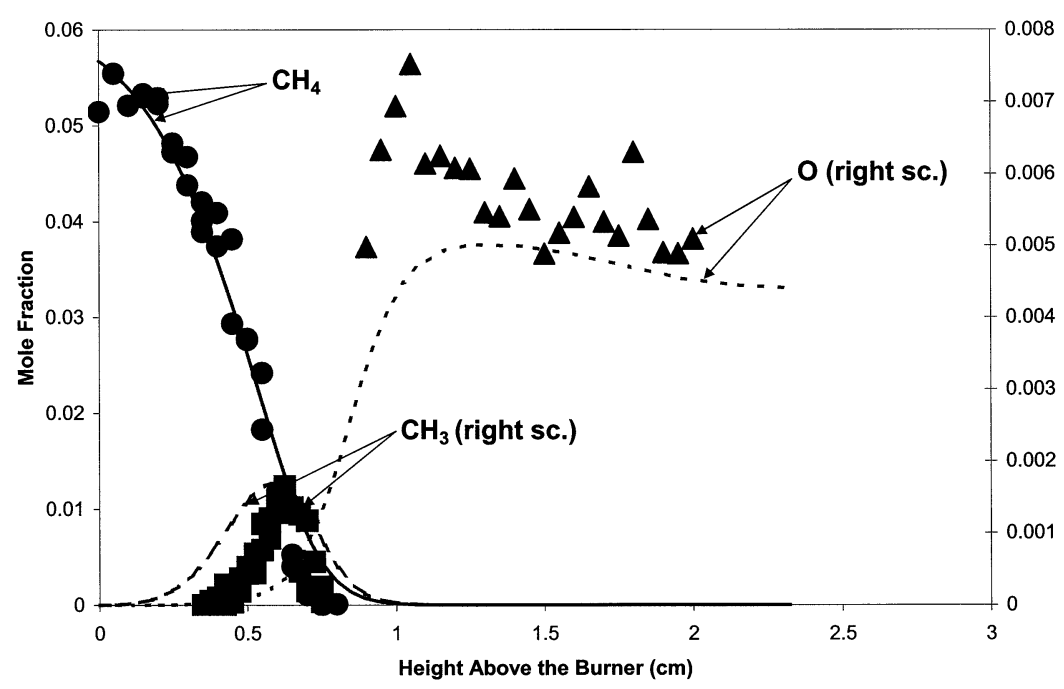

Fig. 5. Comparison between experimental mole fraction profiles and model predictions in a stoichoimetric methane/air/benzene (1.5\%) flame (Flame II).

$\mathrm{CH}_{4}: \bigcirc$ (experiment [20], left scale), — (prediction, left scale)

$\mathrm{CH}_{3}$ : (experiment [20], right scale), - - - (prediction, right scale)

$\mathrm{O}: \boldsymbol{\Delta}$ (experiment [20], right scale), ---- (prediction, right scale).

\subsection{Cyclopentadienyl $\left(\mathrm{c}-\mathrm{C}_{5} \mathrm{H}_{5}\right)$ and cyclopentadiene $\left(c-\mathrm{C}_{5} \mathrm{H}_{6}\right)$}

The analysis of the rates of production of cyclopentadienyl (Fig. 8) and cyclopentadiene (Fig. 9) showed unimolecular decay of phenoxy via (20) to be a major cyclopentadienyl formation route while (21) c- $\mathrm{C}_{5} \mathrm{H}_{5}+\mathrm{H} \leftrightarrows \mathrm{c}-\mathrm{C}_{5} \mathrm{H}_{6}$ was the most important cyclopentadienyl consumption and cyclopentadiene formation reaction. In addition and consistent with its role in phenol depletion, also (19) phenol $\leftrightarrows$ c- $\mathrm{C}_{5} \mathrm{H}_{6}$ $+\mathrm{CO}$ contributes significantly the cyclopentadiene

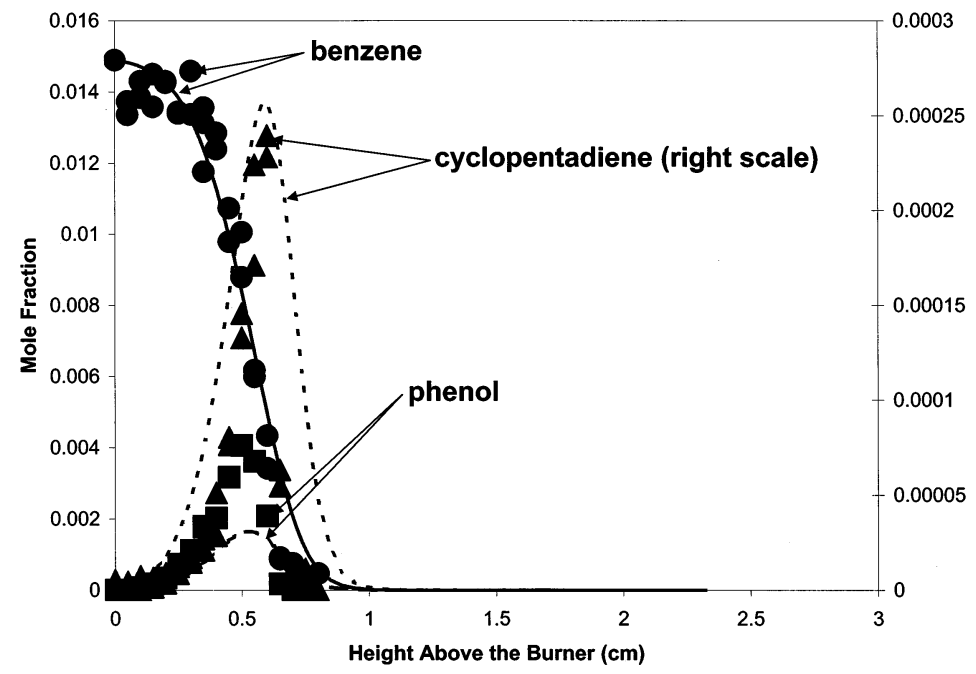

Fig. 6. Comparison between experimental mole fraction profiles and model predictions in a stoichoimetric methane/air/benzene (1.5\%) flame (Flame II).

benzene : (experiment [20], left scale), — (prediction, left scale)

phenol : (experiment [20], left scale), - - - (prediction, left scale)

cyclopentadiene : $\boldsymbol{\Delta}$ (experiment [20], right scale), ---- (prediction, right scale). 
Table 2

Major reactions involved in the depletion of benzene. Rate constants are given as $\mathrm{k}=\mathrm{A} \mathrm{T} \mathrm{T}^{\mathrm{n}} \exp \left(-\mathrm{E}_{\mathrm{a}} / \mathrm{RT}\right)$. Concentrations are expressed in mole $\mathrm{cm}^{-3}$, i.e., A-factors of bimolecular reactions are given in $\mathrm{cm}^{3} \mathrm{~mole}^{-1} \mathrm{~s}^{-1}$.

\begin{tabular}{|c|c|c|c|c|}
\hline Reaction & A & $\mathrm{n}$ & $\mathrm{E}_{a}[\mathrm{cal}]$ & Ref. \\
\hline Benzene $+\mathrm{OH} \leftrightarrows$ phenyl $+\mathrm{H}_{2} \mathrm{O}$ & $2.11 \times 10^{13}$ & 0.0 & 4571 & {$[28]$} \\
\hline Benzene $+\mathrm{O} \leftrightarrows$ phenoxy $+\mathrm{H}$ & $2.40 \times 10^{13}$ & 0.0 & 4668 & {$[29]$} \\
\hline Benzene $+\mathrm{H} \leftrightarrows$ phenyl $+\mathrm{H}_{2}$ & $3.23 \times 10^{7}$ & 2.095 & 15842 & {$[30]^{*}$} \\
\hline Phenyl $+\mathrm{H} \leftrightarrows$ benzene & $8.02 \times 10^{19}$ & -2.011 & 1968 & {$[31]$} \\
\hline Benzene $+\mathrm{OH} \leftrightarrows$ phenol $+\mathrm{H}$ & $1.59 \times 10^{19}$ & -1.82 & 12800 & {$[32]^{* *}$} \\
\hline Phenyl $+\mathrm{O}_{2} \leftrightarrows$ phenoxy $+\mathrm{O}$ & $2.39 \times 10^{21}$ & -2.62 & 4400 & {$[34]^{\dagger}$} \\
\hline Phenyl $+\mathrm{O}_{2} \leftrightarrows$ o-benzoquinone $+\mathrm{H}$ & $3.00 \times 10^{13}$ & 0.0 & 9000 & {$[35]$} \\
\hline Phenyl $+\mathrm{OH} \leftrightarrows$ phenoxy $+\mathrm{H}$ & $5.00 \times 10^{13}$ & 0.0 & 0 & [36] \\
\hline Phenyl $+\mathrm{O} \leftrightarrows \mathrm{c}-\mathrm{C}_{5} \mathrm{H}_{5}+\mathrm{CO}$ & $9.00 \times 10^{13}$ & 0.0 & 0 & [37] \\
\hline $\mathrm{i}-\mathrm{C}_{4} \mathrm{H}_{3}+\mathrm{C}_{2} \mathrm{H}_{3} \leftrightarrows$ phenyl $+\mathrm{H}$ & $6.00 \times 10^{12}$ & 0.0 & 0 & {$[38]$} \\
\hline Phenoxy $+\mathrm{H} \leftrightarrows$ phenol & $4.43 \times 10^{60}$ & -13.232 & 30010 & {$[39]^{*}$} \\
\hline Phenol $+\mathrm{OH} \leftrightarrows$ phenoxy $+\mathrm{H}_{2} \mathrm{O}$ & $1.39 \times 10^{8}$ & 1.43 & -962 & {$[32]$} \\
\hline Phenol $+\mathrm{H} \leftrightarrows$ phenoxy $+\mathrm{H}_{2}$ & $1.15 \times 10^{14}$ & 0.0 & 12400 & [40] \\
\hline Phenol $\leftrightarrows \mathrm{c}-\mathrm{C}_{5} \mathrm{H}_{6}+\mathrm{CO}$ & $1.00 \times 10^{12}$ & 0.0 & 60802 & {$[41]$} \\
\hline Phenoxy $\leftrightarrows \mathrm{c}-\mathrm{C}_{5} \mathrm{H}_{5}+\mathrm{CO}$ & $2.51 \times 10^{11}$ & 0.0 & 43900 & {$[42]$} \\
\hline $\mathrm{c}-\mathrm{C}_{5} \mathrm{H}_{5}+\mathrm{H} \leftrightarrows \mathrm{c}-\mathrm{C}_{5} \mathrm{H}_{6}$ & $2.71 \times 10^{63}$ & -14.79 & 21050 & {$[43]^{\S}$} \\
\hline $\mathrm{c}-\mathrm{C}_{5} \mathrm{H}_{6}+\mathrm{H} \leftrightarrows \mathrm{c}-\mathrm{C}_{5} \mathrm{H}_{5}+\mathrm{H}_{2}$ & $2.80 \times 10^{13}$ & 0.0 & 2259 & [44] \\
\hline $\mathrm{c}-\mathrm{C}_{5} \mathrm{H}_{6}+\mathrm{O} \leftrightarrows \mathrm{c}-\mathrm{C}_{5} \mathrm{H}_{5}+\mathrm{OH}$ & $4.77 \times 10^{4}$ & 2.71 & 1106 & [43] \\
\hline $\mathrm{c}-\mathrm{C}_{5} \mathrm{H}_{6}+\mathrm{OH} \leftrightarrows \mathrm{c}-\mathrm{C}_{5} \mathrm{H}_{5}+\mathrm{H}_{2} \mathrm{O}$ & $3.08 \times 10^{6}$ & 2.00 & 0 & [43] \\
\hline $\mathrm{c}-\mathrm{C}_{5} \mathrm{H}_{5}+\mathrm{O} \leftrightarrows \mathrm{c}-\mathrm{C}_{5} \mathrm{H}_{4} \mathrm{O}+\mathrm{H}$ & $6.71 \times 10^{13}$ & -0.03 & 40 & {$[43]^{\S}$} \\
\hline $\mathrm{c}-\mathrm{C}_{5} \mathrm{H}_{4} \mathrm{O}+\mathrm{H} \leftrightarrows \mathrm{n}-\mathrm{C}_{4} \mathrm{H}_{5}+\mathrm{CO}$ & $2.10 \times 10^{61}$ & -13.27 & 40810 & {$[35]$} \\
\hline $\mathrm{c}-\mathrm{C}_{5} \mathrm{H}_{5}+\mathrm{OH} \leftrightarrows \mathrm{c}-\mathrm{C}_{5} \mathrm{H}_{4}+\mathrm{H}_{2} \mathrm{O}$ & $2.11 \times 10^{13}$ & 0.0 & 4571 & {$[28]^{* * *} *$} \\
\hline $\mathrm{c}-\mathrm{C}_{5} \mathrm{H}_{5}+\mathrm{H} \leftrightarrows \mathrm{c}-\mathrm{C}_{5} \mathrm{H}_{4}+\mathrm{H}_{2}$ & $3.23 \times 10^{7}$ & 2.095 & 15842 & {$[30]^{\dagger \dagger}$} \\
\hline $\mathrm{c}-\mathrm{C}_{5} \mathrm{H}_{5}+\mathrm{O} \leftrightarrows \mathrm{n}-\mathrm{C}_{4} \mathrm{H}_{5}+\mathrm{CO}$ & $7.27 \times 10^{13}$ & -0.28 & 470 & {$[43]^{\S}$} \\
\hline $\mathrm{c}-\mathrm{C}_{5} \mathrm{H}_{6}+\mathrm{H} \leftrightarrows \mathrm{C}_{3} \mathrm{H}_{5}+\mathrm{C}_{2} \mathrm{H}_{2}$ & $6.60 \times 10^{14}$ & 0.0 & 12345 & {$[44]$} \\
\hline $\mathrm{o}-\mathrm{C}_{6} \mathrm{H}_{4} \mathrm{O}_{2} \leftrightarrows \mathrm{c}-\mathrm{C}_{5} \mathrm{H}_{4} \mathrm{O}+\mathrm{CO}$ & $1.00 \times 10^{12}$ & 0.0 & 40000 & [35] \\
\hline
\end{tabular}

* deduced by via the equilibrium constant of Benzene $+\mathrm{H} \leftrightarrows$ phenyl $+\mathrm{H}_{2}$ using the rate constant determined by Mebel et al. [30]; ** Quantum Rice-Ramsperger-Kassel (QRRK) analysis at 20 torr based on Shandross et al. [32] using improved treatment allowing for three frequencies as input [23]. The rate constant at the high-pressure limit of the benzene $+\mathrm{OH}$ reaction, i.e., $1.39 \times 10^{12} \exp (-0.38 \mathrm{kcal} / \mathrm{RT}) \mathrm{cm}^{3} \mathrm{~mole}^{-1} \mathrm{~s}^{-1}$ was taken from Witte et al. [33]; ${ }^{\dagger} \mathrm{QRRK}$ analysis [23] at 20 torr using the input parameters suggested by Dinaro et al. [34]; ${ }^{\ddagger}$ QRRK analysis [23] at 20 torr using $2.50 \times 10^{14} \mathrm{~cm}^{3} \mathrm{~mole}^{-1} \mathrm{~s}^{-1}$ [39] as high pressure limit. No additional exit channel, i.e., only stabilization to phenol and the decay to the reactants (phenoxy + H) are taken into account; ${ }^{\S}$ QRRK analysis [23] at 20 torr using the input parameters provided by Zhong and Bozzelli [43]; $* * *$ rate constant for Benzene $+\mathrm{OH} \leftrightarrows$ phenyl $+\mathrm{H}_{2} \mathrm{O} ;{ }^{\dagger \dagger}$ rate constant for Benzene $+\mathrm{H} \leftrightarrows$ phenyl $+\mathrm{H}_{2}$.

formation. The chemistries of cyclopentadiene and cyclopentadienyl are strongly coupled, hydrogen abstractions from cyclopentadiene (22) $\mathrm{c}-\mathrm{C}_{5} \mathrm{H}_{6}+\mathrm{H} \leftrightarrows$ $\mathrm{c}-\mathrm{C}_{5} \mathrm{H}_{5}+\mathrm{H}_{2}$, (23) $\mathrm{c}-\mathrm{C}_{5} \mathrm{H}_{6}+\mathrm{O} \leftrightarrows \mathrm{c}-\mathrm{C}_{5} \mathrm{H}_{5}+\mathrm{OH}$ and (24) $\mathrm{c}-\mathrm{C}_{5} \mathrm{H}_{6}+\mathrm{OH} \leftrightarrows \mathrm{c}-\mathrm{C}_{5} \mathrm{H}_{5}+\mathrm{H}_{2} \mathrm{O}$ play a significant role in $\mathrm{c}-\mathrm{C}_{5} \mathrm{H}_{6}$ consumption and $\mathrm{c}-\mathrm{C}_{5} \mathrm{H}_{5}$ formation. In agreement with its role in phenyl con-

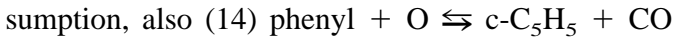
$[19,37]$ contributes to the formation of cyclopentadienyl. Oxidation of cyclopentadienyl to cyclopentadienone $\left(\mathrm{c}-\mathrm{C}_{5} \mathrm{H}_{4} \mathrm{O}\right),(25) \mathrm{c}-\mathrm{C}_{5} \mathrm{H}_{5}+\mathrm{O} \leftrightarrows \mathrm{c}-\mathrm{C}_{5} \mathrm{H}_{4} \mathrm{O}+\mathrm{H}$ was found to be a major $\mathrm{c}-\mathrm{C}_{5} \mathrm{H}_{5}$ consumption pathway. The rate constant of (25) [19,24] was determined by means of a QRRK computation [23] using the input parameters given by Zhong and Bozzelli [43]. Analysis of the rates of production of $\mathrm{c}-\mathrm{C}_{5} \mathrm{H}_{4} \mathrm{O}$ allowed for the identification of n-butadienyl forma- tion, (26) $\mathrm{c}-\mathrm{C}_{5} \mathrm{H}_{4} \mathrm{O}+\mathrm{H} \leftrightarrows \mathrm{n}-\mathrm{C}_{4} \mathrm{H}_{5}+\mathrm{CO}$, as its dominant consumption pathway. Other, secondary, cyclopentadienyl consumption pathways are hydrogen abstraction to cyclopentatriene $\left(\mathrm{c}-\mathrm{C}_{5} \mathrm{H}_{4}\right),(27)$ $\mathrm{c}-\mathrm{C}_{5} \mathrm{H}_{5}+\mathrm{OH} \leftrightarrows \mathrm{c}-\mathrm{C}_{5} \mathrm{H}_{4}+\mathrm{H}_{2} \mathrm{O}$ and (28) $\mathrm{c}-\mathrm{C}_{5} \mathrm{H}_{5}+$ $\mathrm{H} \leftrightarrows \mathrm{c}-\mathrm{C}_{5} \mathrm{H}_{4}+\mathrm{H}_{2}$ as well as its oxidation to nbutadienyl (29) $\mathrm{c}-\mathrm{C}_{5} \mathrm{H}_{5}+\mathrm{O} \leftrightarrows \mathrm{n}-\mathrm{C}_{4} \mathrm{H}_{5}+\mathrm{CO}$. Besides hydrogen abstraction to cyclopentadienyl, (22) - (24), decomposition of cyclcopentadiene to propyl $\left(\mathrm{C}_{3} \mathrm{H}_{5}\right)$ and acetylene, (30) $\mathrm{c}-\mathrm{C}_{5} \mathrm{H}_{6}+\mathrm{H} \leftrightarrows \mathrm{C}_{3} \mathrm{H}_{5}+$ $\mathrm{C}_{2} \mathrm{H}_{2}$ is its major depletion pathway. Despite a predicted peak mole fraction of $\approx 2 \times 10^{-4}$, no experimental cyclopentadienyl profile was available in the present work but the excellent agreement between the computed and experimental cyclopentadiene profiles (Fig. 6) indicates a realistic description of the $\mathrm{C}_{5}$ chemistry by the kinetic model $[19,24]$. This finding 


\section{Methane/Air + Benzene Flame (phi= 1.0) Rates of Production : Benzene $\left(\mathrm{C}_{6} \mathrm{H}_{6}\right)$}

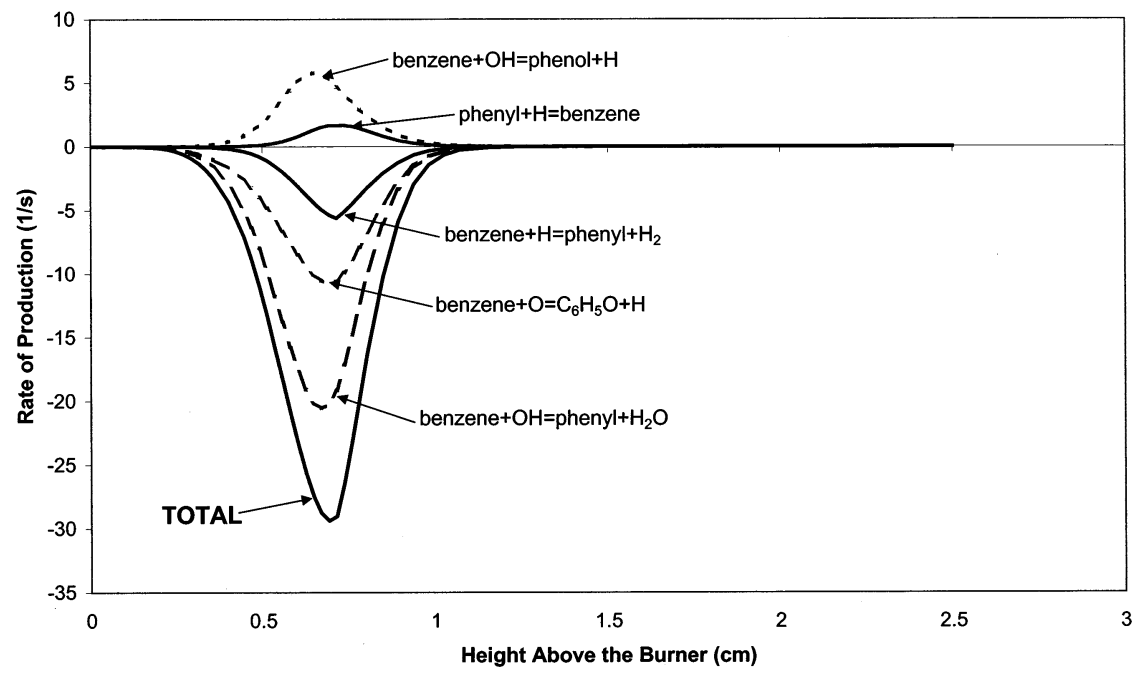

Fig. 7. Rates of production of benzene in a stoichoimetric methane/air/benzene (1.5\%) flame (Flame II).

is consistent with the previous modeling of premixed low-pressure acetylene [19] and benzene [18,19] flames.

However, open questions remain concerning the link between cyclic $\mathrm{C}_{6}$ and $\mathrm{C}_{5}$ species. For instance, the overpredictions of phenoxy and cyclopentadienone described recently [19] need to be addressed in future work. Unimolecular decay of o-benzoquinone $\left(\mathrm{o}-\mathrm{C}_{6} \mathrm{H}_{4} \mathrm{O}_{2}\right)$, (31) o- $\mathrm{C}_{6} \mathrm{H}_{4} \mathrm{O}_{2} \leftrightarrows \mathrm{c}-\mathrm{C}_{5} \mathrm{H}_{4} \mathrm{O}+\mathrm{CO}$, suggested by Alzueta et al. [35], was found to be a major cyclopentadienone formation pathway and additional work on benzoquinone formation and consumption is required.

It is worthwhile to mention that even at stoichiometric conditions, as investigated in the present work, non-negligible amounts of small $\mathrm{PAH}$ can be formed in the flame front. Naphthalene $\left(\mathrm{C}_{10} \mathrm{H}_{8}\right)$ and phenanthrene $\left(\mathrm{C}_{14} \mathrm{H}_{10}\right)$ were predicted to be formed with peak mole fractions of $\approx 1 \times 10^{-6}$ and $\approx 1 \times$ $10^{-7}$, respectively, followed by complete depletion in the postflame zone.

\subsection{Aliphatic oxygenated species: acetaldehyde, dimethylether, propanal and 2-propenal}

The use of gas chromatography coupled to mass spectrometry (GC-MS) allowed for the unambiguous identification of oxygen containing species. Mole fraction profiles of dimethylether $\left(\mathrm{CH}_{3} \mathrm{OCH}_{3}\right)$ and acetaldehyde $\left(\mathrm{CH}_{3} \mathrm{CHO}\right)$ measured in the benzeneseeded stoichiometric methane/air flame are plotted in Fig. 10 and compared to model predictions. Shape and peak location of both species were correctly predicted, but a two-fold overprediction of the peak value occurred for dimethylether if the rate constant $\mathrm{k}=1.21 \times 10^{13} \mathrm{~cm}^{3}$ mole $\mathrm{s}^{-1} \mathrm{~s}^{-1}$, recommended by Tsang and Hampson [45], was used for (32) $\mathrm{CH}_{3}+$ $\mathrm{CH}_{3} \mathrm{O} \leftrightarrows \mathrm{CH}_{3} \mathrm{OCH}_{3}$. The analysis of rates of production showed reaction of methoxy $\left(\mathrm{CH}_{3} \mathrm{O}\right)$ with methyl $\left(\mathrm{CH}_{3}\right)$, (32), to be the only dimethylether formation pathway. The reverse reaction is the most important single dimethylether consumption reaction, the rate of production of (32) is negative at 6.5 $\mathrm{mm}$ from the burner and beyond. In addition, hydrogen abstraction with $\mathrm{H}, \mathrm{O}$ and $\mathrm{OH}$ plays a significant role in dimethylether consumption. The resulting $\mathrm{CH}_{3} \mathrm{OCH}_{2}$ decays subsequently to methyl and formaldehyde $\left(\mathrm{CH}_{2} \mathrm{O}\right)$, (33) $\mathrm{CH}_{3} \mathrm{OCH}_{2} \leftrightarrows \mathrm{CH}_{3}+\mathrm{CH}_{2} \mathrm{O}$. The two-fold overprediction of dimethylether is likely to be related to a decrease of $k_{32}$ at higher temperature due to chemical activation and an increasing contribution of the reverse reaction, in particular at low-pressure conditions. A similar behavior was observed for the self-combination of phenyl to biphenyl [18] and, similar to this case, a QRRK computation [23] for reaction (32) was performed in the present work. $\mathrm{k}_{32}=7.6910^{58} \mathrm{~T}^{-14.14} \exp (-17.84$ $\mathrm{kcal} / \mathrm{RT}) \mathrm{cm}^{3} \mathrm{~mole}^{-1} \mathrm{~s}^{-1}$ at $5.33 \mathrm{kPa}$ resulted from the QRRK treatment exhibiting a pronounced decrease with increasing temperature. Its use in the kinetic model led to a significant reduction of the peak mole fraction (Fig. 10) but did not effect the prediction of methyl, in excellent agreement with the experimental data. 
Methane/Air + Benzene Flame (phi= 1.0) Rates of Production : Cyclopentadienyl $\left(\mathrm{c}-\mathrm{C}_{5} \mathrm{H}_{5}\right)$

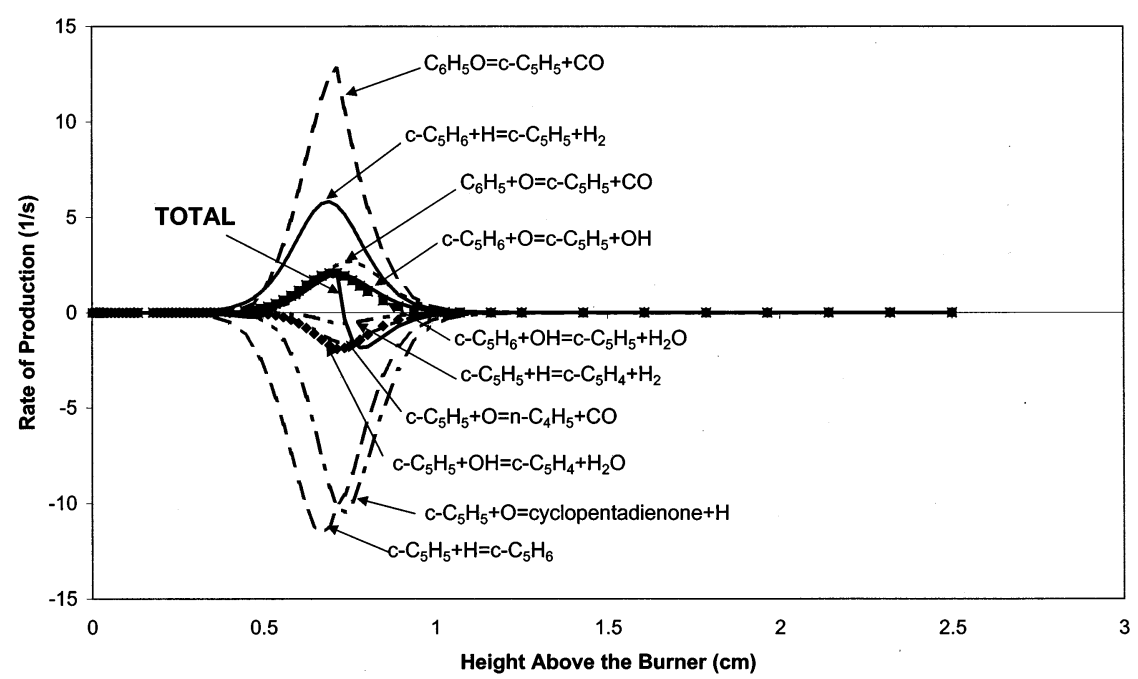

Fig. 8. Rates of production of cyclopentadienyl radicals in a stoichoimetric methane/air/benzene (1.5\%) flame (Flame II).

Oxidation of vinyl $\left(\mathrm{C}_{2} \mathrm{H}_{3}\right)$ by $\mathrm{OH},(33) \mathrm{C}_{2} \mathrm{H}_{3}+$ $\mathrm{OH} \leftrightarrows \mathrm{CH}_{3} \mathrm{CHO}$ was found to be a major formation route of acetaldehyde $\left(\mathrm{CH}_{3} \mathrm{CHO}\right)$. The reaction of methyl with formyl (HCO) radicals, ie, the reverse of (34) $\mathrm{C}_{2} \mathrm{H}_{3}+\mathrm{OH} \leftrightarrows \mathrm{CH}_{3} \mathrm{CHO}$, contributed significantly to acetaldehyde formation in the first part of the reaction zone but became a consumption pathway beyond about $7 \mathrm{~mm}$ from the burner. Hydrogen ab- stractions from the aldehyde group by $\mathrm{H}, \mathrm{O}$ and $\mathrm{OH}$ were identified as dominant consumption routes. The resulting $\mathrm{CH}_{3} \mathrm{CO}$ decays readily via $(35) \mathrm{CH}_{3} \mathrm{CHO}$ $\leftrightarrows \mathrm{CH}_{3}+\mathrm{HCO}$, a peak mole fraction of only 1.5 $10^{-10}$ was predicted by the model.

Mole fraction profiles of two three carbon atom containing aldehydes, propanal $\left(\mathrm{C}_{2} \mathrm{H}_{5} \mathrm{CHO}\right)$ and 2-propenal $\left(\mathrm{CH}_{2} \mathrm{CHCHO}\right.$, acrolein), were measured

\section{Methane/Air + Benzene Flame (phi= 1.0) Rates of Production : Cyclopentadiene $\left(\mathrm{c}-\mathrm{C}_{5} \mathrm{H}_{6}\right)$}

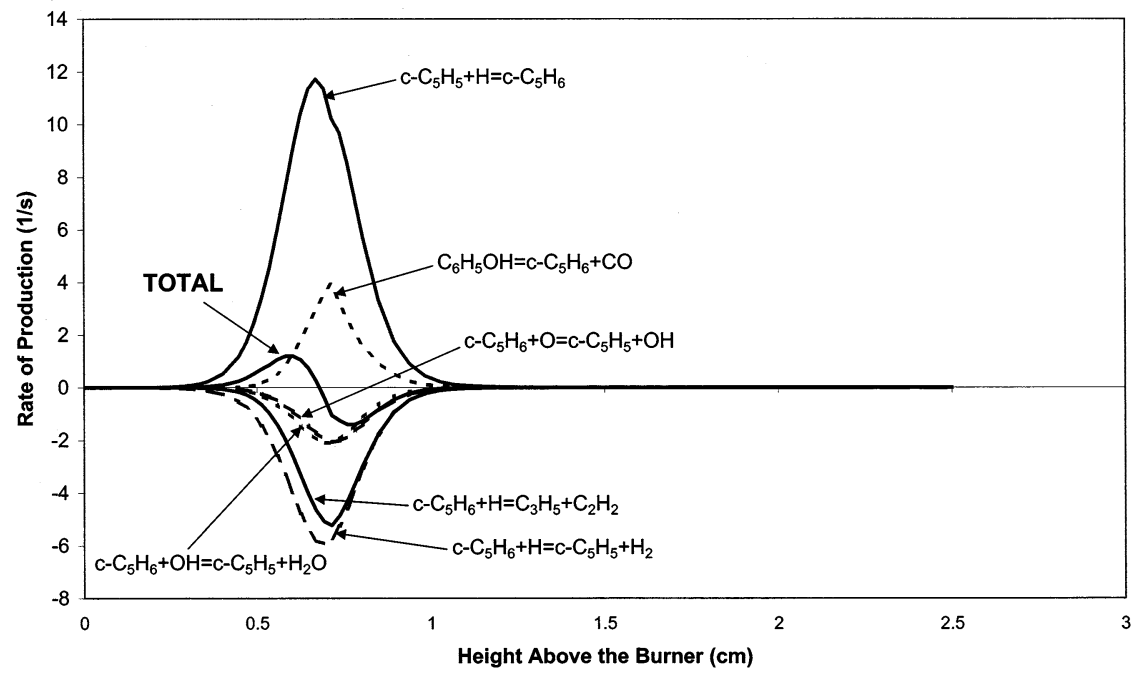

Fig. 9. Rates of production of cyclopentadiene in a stoichoimetric methane/air/benzene (1.5\%) flame (Flame II). 


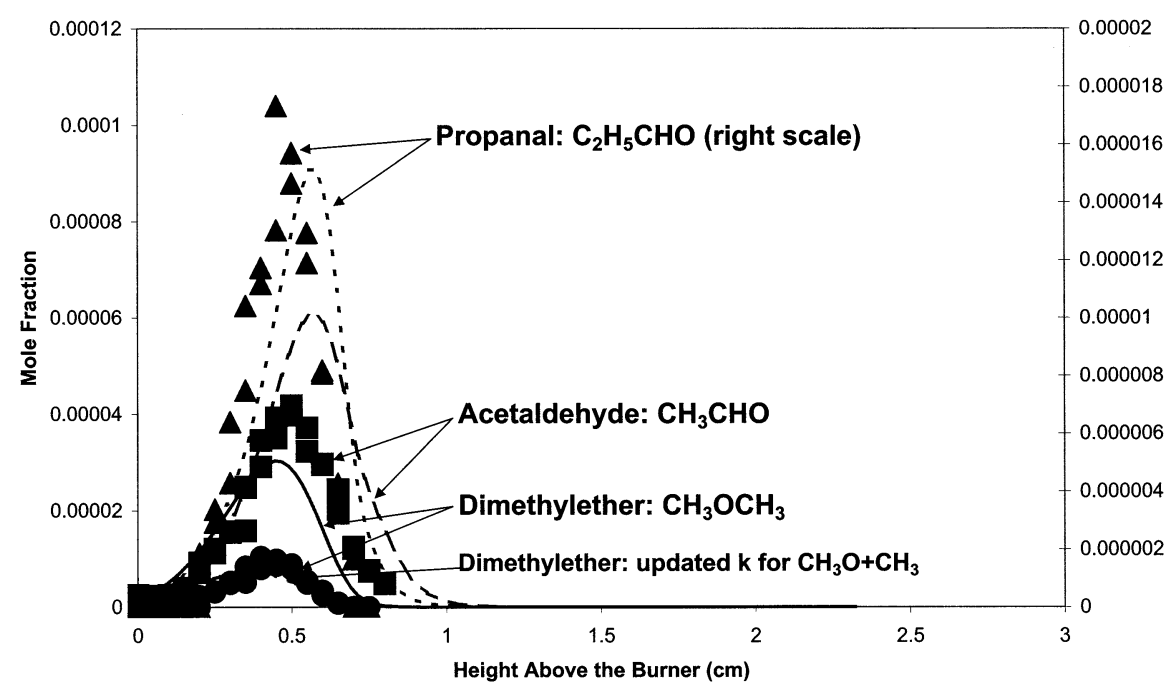

Fig. 10. Comparison between experimental mole fraction profiles and model predictions in a stoichioimetric methane/air/ benzene $(1.5 \%)$ flame (Flame II).

dimethylether $\left(\mathrm{CH}_{3} \mathrm{OCH}_{3}\right)$ : (experiment [20], left scale), - (prediction, using

$\mathrm{k}_{32}=1.21 \times 10^{13} \mathrm{~cm}^{3}$ mole $^{-1} \mathrm{~s}^{-1}$ [45], left scale),

$-\cdot-\cdot-$ (prediction, using $\mathrm{k}_{32}=7.69 \times 10^{58} \mathrm{~T}^{-14.14}$

$\exp (-17.84 \mathrm{kcal} / \mathrm{RT}) \mathrm{cm}^{3} \mathrm{~mole}^{-1} \mathrm{~s}^{-1}$, left scale)

acetaldehyde $\left(\mathrm{CH}_{3} \mathrm{CHO}\right):-$ (experiment [20], left scale), - - - (prediction, left scale)

propanal $\left(\mathrm{C}_{2} \mathrm{H}_{5} \mathrm{CHO}\right)$ : $\boldsymbol{\Delta}$ (experiment [20], right scale), ---- (prediction, right scale).

with GC-MS. Shape and peak values of both species were well predicted but a shift of the computed profiles relative to the experimental ones toward the postflame zone by 1 to $2 \mathrm{~mm}$ occurred. Both experimental and predicted profiles of propanal are given in Fig. 10. Reaction of propyl $\left(\mathrm{C}_{3} \mathrm{H}_{5}\right)$ with $\mathrm{OH}$, (36) $\mathrm{CH}_{3} \mathrm{CO} \leftrightarrows \mathrm{CH}_{3}+\mathrm{CO}$ was found to be the dominant propanal formation pathway. Its consumption occurs through unimolecular decay to ethyl $\left(\mathrm{C}_{2} \mathrm{H}_{5}\right)$ and formyl (HCO), ie, the reverse of reaction (37) $\mathrm{C}_{3} \mathrm{H}_{5}$ $+\mathrm{OH} \leftrightarrows \mathrm{C}_{2} \mathrm{H}_{5} \mathrm{CHO}$, and hydrogen abstraction by $\mathrm{OH}$ from the aldehyde group, (38) $\mathrm{C}_{2} \mathrm{H}_{5}+\mathrm{HCO} \leftrightarrows$ $\mathrm{C}_{2} \mathrm{H}_{5} \mathrm{CHO}$. The resulting radical decays quantitatively to ethyl and $\mathrm{CO}$. Its rates of production show 2-propenal $\left(\mathrm{CH}_{2} \mathrm{CHCHO}\right)$ to be formed by oxidation of propyl and propargyl $\left(\mathrm{C}_{3} \mathrm{H}_{3}\right)$ by reaction with $\mathrm{O}$ and $\mathrm{OH}$, ie, (39) $\mathrm{C}_{2} \mathrm{H}_{5} \mathrm{CHO}+\mathrm{OH} \leftrightarrows \mathrm{C}_{2} \mathrm{H}_{5} \mathrm{CO}+$ $\mathrm{H}_{2} \mathrm{O}$ and (40) $\mathrm{C}_{3} \mathrm{H}_{5}+\mathrm{O} \leftrightarrows \mathrm{CH}_{2} \mathrm{CHCHO}+\mathrm{H}$. Hydrogen abstraction from the aldyhyde group and unimolecular decay to vinyl and formyl, (42) $\mathrm{C}_{2} \mathrm{H}_{3}+$ $\mathrm{HCO} \leftrightarrows \mathrm{CH}_{2} \mathrm{CHCHO}$, are its major consumption pathways.

\section{Conclusions}

A recently developed kinetic model was used for the assessment of major reaction pathways in two laminar premixed flat stoichiometric methane/air low pressure flames with and without the addition of $1.5 \%$ of benzene. Mole fraction profiles for stable and unstable species including radicals were measured previously by molecular beam sampling coupled to mass spectrometry and allowed for a thorough testing of the kinetic model. Mole fraction profiles established by means of gas chromatographic analysis (GC-TCD-FID, GC-MS) were available and made the inambiguous identification of structural isomers, e.g., cyclic and aliphatic $\mathrm{C}_{6} \mathrm{H}_{6}$ or $\mathrm{C}_{5} \mathrm{H}_{5}$, possible. Good to excellent agreements between predictions and measured mole fraction profiles were obtained for reactants, intermediates and products such as methane, $\mathrm{O}_{2}$, methyl, $\mathrm{H}, \mathrm{OH}, \mathrm{CO}, \mathrm{CO}_{2}$, and $\mathrm{H}_{2} \mathrm{O}$. Benzene depletion as well as the formation and consumption of intermediates such as cyclopentadiene were predicted correctly. Reaction pathways responsible for the formation and consumption of selected species were identified by means of the analysis of their rates of production. Methane consumption was found to be initiated by hydrogen abstraction with $\mathrm{H}$, $\mathrm{OH}$ and $\mathrm{O}$ while the resulting methyl radicals were oxidized by reaction with $\mathrm{O}$ to formyl, (1) $\mathrm{CH}_{3}+\mathrm{O}$ $\leftrightarrows \mathrm{HCO}+\mathrm{H}_{2}$, and formaldehyde, (2) $\mathrm{CH}_{3}+\mathrm{O} \leftrightarrows$ $\mathrm{CH}_{2} \mathrm{O}+\mathrm{H}$. Subsequent hydrogen abstractions by $\mathrm{H}$ and $\mathrm{OH}$ from $\mathrm{CH}_{2} \mathrm{O}$ and $\mathrm{HCO}$ as well as unimolecular hydrogen loss from $\mathrm{HCO}$ led finally to $\mathrm{CO}$, par- 
tially oxidized by $\mathrm{OH}$ to $\mathrm{CO}_{2}$. Benzene consumption occurred mainly by hydrogen abstraction with $\mathrm{OH}$ and $\mathrm{H}$ as reactant but also the contribution of its oxidation by $\mathrm{O}$ to phenoxy is significant. Reaction of phenyl with $\mathrm{O}_{2}$ was identified to be a major phenyl consumption and phenoxy formation pathway. Phenol and phenoxy chemistries are strongly coupled, unimolecular decay of phenoxy to cyclopentadienyl radicals and $\mathrm{CO}$ is the dominant consumption route. Cyclopentadiene was formed from cyclopentadienyl but also by phenol decomposition, (19) phenol $\leftrightarrows$ $\mathrm{C}_{5} \mathrm{H}_{6}+\mathrm{CO}$. Naphthalene $\left(\mathrm{C}_{10} \mathrm{H}_{8}\right)$ and phenanthrene $\left(\mathrm{C}_{14} \mathrm{H}_{10}\right)$ were predicted to be formed in the reaction zone, followed by complete depletion in the postflame region. The formation and depletion of the aliphatic oxygenated species acetaldehyde, dimethylether, propanal and 2-propenal were correctly reproduced by the model. The pressure dependence of the dominant dimethylether formation pathway (32) $\mathrm{CH}_{3}$ $+\mathrm{CH}_{3} \mathrm{O} \leftrightarrows \mathrm{CH}_{3} \mathrm{OCH}_{3}$ was found to be significant and was assessed by means of a Quantum RiceRamsperger-Kassel (QRRK) analysis.

\section{Acknowledgments}

In the USA, this research was supported by the Chemical Sciences Division, Office of Basic Energy Sciences, Office of Energy Research, U.S. Department of Energy under Grant DE-FGO2 to 84ER13282. Prof. J. B. Howard is acknowledged for many helpful discussions. Prof. W. H. Green, Dr. O. Mazyar and Dr. R. Sumathi are thanked for their contributions to the development of the thermodynamic and kinetic property data sets. The authors thank Prof. J. W. Bozzelli for providing software and valuable advice. One of the authors (H.R.) thanks the Université des Sciences et Technologies de Lille for its generous invitation.

In France, this research was supported by Gaz de France. The authors are also grateful to the "Ministère de la Recherche et de l'Enseignement Supérieur", the "Région Nord/Pas de Calais", and the "Fonds Européens de Développement Economique des Régions (FEDER)" for partial funding of this work and for supporting CERLA.

\section{References}

[1] D.W. Dockery, C.A. Pope, X. Xu, J.D. Spengler, J.H. Ware, M.E. Fay, B.G. Ferris, F.E. Speizer, N. Engl. J. Med. 329 (1993) 1753-1759.

[2] N. Künzli, R. Kaiser, S. Medina, M. Studnicka, O. Chanel, P. Filliger, M. Herry, F. Horak Jr., V. Puybonnieux-Texier, P. Quénel, J. Schneider, R. Seetha- ler, J.-C. Vergnaud, H. Sommer, Lancet 356 (2000) 795-801.

[3] H. Richter, J.B. Howard, Prog. Energy Combust. Sci. 26 (2000) 565-608.

[4] J.O. Allen, N.M. Dookeran, K.A. Smith, A.F. Sarofim, K. Taghizadeh, A.L. Lafleur, Environ. Sci. Technol. 30 (1996) 1023-1031.

[5] J.L. Durant, W.F. Busby, A.L. Lafleur, B.W. Penman, C.L. Crespi, Mutation Research 371 (1996) 123-157.

[6] N.M. Marinov, W.J. Pitz, C.K. Westbrook, M.J. Castaldi, S M. Senkan, Combust. Sci. Technol. 116117 (1996) 211-287.

[7] H. Wang, M. Frenklach, Combust. Flame 110 (1997) 173-221.

[8] R.P. Lindstedt, G. Skevis, Combust. Sci. Technol. 125 (1997) 73-137.

[9] A.D'Anna, A. Violi, Twenty-Seventh Symposium (International) on Combustion, The Combustion Institute, Pittsburgh, 1998, p. 425-433.

[10] T. Faravelli, A. Goldaniga, E. Ranzi, Twenty-Seventh Symposium (International) on Combustion, The Combustion Institute, Pittsburgh, 1998, p. 1489-1495.

[11] N.M. Marinov, M.J. Castaldi, C.F. Melius, W. Tsang, Combust. Sci. Technol. 128 (1997) 295-342.

[12] R.P. Lindstedt, G. Skevis, Twenty-Sixth Symposium (International) on Combustion, The Combustion Institute, Pittsburgh, 1996, p. 703-709.

[13] A. Goldaniga, T. Faravelli, E. Ranzi, Combust. Flame 122 (2000) 350-358.

[14] R.P. Lindstedt, G. Skevis, Combust. Flame 99 (1994) 551-561.

[15] H.-Y. Zhang, J.T. McKinnon, Combust. Sci. Technol. 107 (1995) 261-300.

[16] Y. Tan, P. Frank, Twenty-Sixth Symposium (International) on Combustion, The Combustion Institute, Pittsburgh, 1996, p. 677-684.

[17] H. Richter, W.J. Grieco, J.B. Howard, Combust. Flame 119 (1999) 1-22.

[18] H. Richter, T.G. Benish, O.A. Mazyar, W.H. Green, J.B. Howard, Proc. Combust. Inst. 28 (2000) 26092618.

[19] H. Richter, J.B. Howard, Phys. Chem. Chem. Phys. 4 (2002) 2038-2055.

[20] L. Dupont, Etude expérimentale et modélisation cinétique de la dégradation thermique des composés organiques volatils aromatiques benzène, toluène et para-xylène dans des flames de méthane. Ph. D. thesis, Université des Sciences et Technologies de Lille, February, 2001.

[21] B. Crunelle, A. Turbiez, J.-F. Pauwels, J. Chim. Phys. 94 (1997) 433-459.

[22] B. Crunelle, A. Turbiez, J.-F. Pauwels, J. Chim. Phys. 96 (1999) 1146-1171.

[23] A.Y. Chang, J.W. Bozzelli, A.M. Dean, Z. Phys. Chem. 214 (2000) 1533-1568.

[24] http://web.mit.edu/anish/www/MITcomb.html.

[25] R.J. Kee, F.M. Rupley, J.A. Miller, M.E. Coltrin, J.F. Grcar, E. Meeks, H.K. Moffat, A.E. Lutz, G. DixonLewis, M.D. Smooke, J. Warnatz, G.H. Evans, R S. Larson, R.E. Mitchell, L R. Petzold, W.C. Reynolds, M. Caracotsios, W.E. Stewart, P. Glarborg, C. Wang, 
O. Adigun, CHEMKIN Collection, Release 3.6, Reaction Design, Inc., San Diego, CA, 2000.

[26] K.P. Lim, J.V. Michael, J. Chem. Phys. 98 (1993) 3919-3928.

[27] T.P. Marcy, R.R. Dìaz, D. Heard, S.R. Leone, L.B. Harding, S.J. Klippenstein, J. Phys. Chem. A 105 (2001) 8361-8369.

[28] S. Madronich, W. Felder, J. Phys. Chem. 89 (1985) 3556-3561.

[29] T. Ko, G.Y. Adusei, A. Fontijn, J. Phys. Chem. 95 (1991) 8745-8748

[30] A.M. Mebel, M.C. Lin, T. Yu, K. Morokuma, J. Phys. Chem. A 101 (1997) 3189-3196.

[31] A.M. Mebel, M.C. Lin, D. Chakraborty, J. Park, S.H. Lin, Y.T. Lee, J. Chem. Phys. 114 (2001) 8421-8435.

[32] R.A. Shandross, J. P. Longwell, J.B. Howard, TwentySixth Symposium (International) on Combustion, The Combustion Institute, Pittsburgh, 1996, p. 711-719.

[33] F. Witte, E. Urbanik, C. Zetzsch, J. Phys. Chem. 90 (1986) 3251-3259.

[34] J.L. DiNaro, J.B. Howard, W.H. Green, J.W. Tester, J.W. Bozzelli, J. Phys. Chem. A 104 (2000) 1057610586.

[35] M.U. Alzueta, P. Glarborg, K. Dam-Johansen, Int. J. Chem. Kinet. 32 (2000) 498-522.
[36] J.A. Miller, C.F. Melius, Combust. Flame 91 (1992) 21-39.

[37] P. Frank, J. Herzler, Th. Just, C. Wahl, Th. Just, C. Wahl, Twenty-Fifth Symposium (International) on Combustion, The Combustion Institute, Pittsburgh, 1994, p. 833-840.

[38] C.J. Pope, J.A. Miller, Proc. Combust. Inst. 28 (2000) 1519-1527.

[39] S.G. Davis, H. Wang, K. Brezinsky, C.K. Law, TwentySixth Symposium (International) on Combustion, The Combustion Institute, Pittsburgh, 1996, p. 1025-1033.

[40] J.L. Emdee, K. Brezinsky, I. Glassman, J Phys. Chem. 96 (1992) 2151-2161.

[41] C. Horn, K. Roy, P. Frank, Th. Just, Twenty-Seventh Symposium (International) on Combustion, The Combustion Institute, Pittsburgh, 1998, p. 321-328.

[42] C.-Y. Lin, M. C. Lin, J. Phys. Chem. 90 (1986) 425431.

[43] X. Zhong, J W. Bozzelli, J. Phys. Chem. A 102 (1998) 3537-3555.

[44] K. Roy, C. Horn, V.G. Slutsky, Th. Just, TwentySeventh Symposium (International) on Combustion, The Combustion Institute, Pittsburgh, 1998, p. 329336.

[45] W. Tsang, R.F. Hampson, J. Phys. Chem. Ref. Data 15 (1986) 1087. 